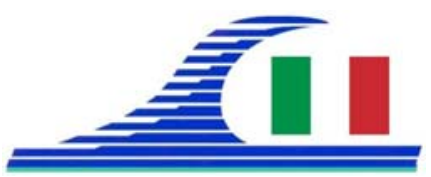

\title{
Rheological behaviour of marine sediments for assessing nautical depth
}

\author{
Ahmed BENAMAR ${ }^{1}$, Anne PANTET ${ }^{1}$, Sébastien BRASSELET ${ }^{2}$, Frédérique BOURDIN $^{2}$ \\ 1. LOMC UMR 6294 CNRS-Univ. du Havre 53 rue de Prony 76600 Le Havre, France. \\ benamar@univ-lehavre.fr ; anne.pantet@univ-lehavre.fr \\ 2. GPMH, port authority, service AEM, Terreplein de la Barre 7600 Le Havre, France. \\ sebastien.brasselet@havre-port.fr ; frederique.bourdin@havre-port.fr
}

\begin{abstract}
:
Dredging practices constitute a challenge for developing and maintaining harbour and fluvial activities. They also present a contamination risk of coastal waters which can affect the ecosystems. The unsuitability and restriction to marine disposal of dredged sediments leads ultimately the managers to provide a treatment ashore because of the great volume to be treated. The first concepts to reduce the considerable amounts of sediment were drawn up. Remediation techniques are available and can remove, reduce, immobilise or confine the pollutants. Selection of these techniques depends upon the management policy being applied at each site. The need for maintaining safely navigable waterways in the most efficient way leads to think about in-situ solution which keeps up the sediments. The nautical bottom concept was developed and implemented in several major ports. This concept however requires dedicated measurements of the rheological conditions. In order to assess the nautical depth for dredged sediments from Le Havre (France) harbour, shearing tests using a rheometer were carried out in laboratory. The computed viscosity curves (flow curves) were derived from measured corresponding shear rate value. These curves show that this mud material will be able to flow when external shear stress exceeds a threshold value which is close to $30 \mathrm{~Pa}$ and this mud will lose its internal strength completely at shear stress values of about $150 \mathrm{~Pa}$. This means that in situ sediment conditioning will principally be applicable to this mud (mainly silt) material. The long experience of maintenance dredging in Emden (Germany) port has shown that a highly effective technique to achieve and to keep the navigability of corresponding mud material can be applied.
\end{abstract}

Keywords: Sediment, Dredging, Rheology, Waterway, Nautical-depth, Viscosity.

\section{Introduction}

The costs of maintaining the nautical depths in the ports are significant, and authorities issued alternative solutions in order to avoid marine exclusive deposit. These costs will increase exponentially when deeper access channels are to be maintained. The ongoing capacity increase of both transport modalities and harbours therefore trigger the need for maintaining safely navigable waterways in the most efficient way. In this perspective the 
Côtes méditerranéennes menacées :

Risques et défis dans le contexte du changement climatique

nautical bottom concept was developed and implemented in several major ports. This concept is valid because the top layer of the siltation material has, in general, such low strength characteristics that it does not cause problems for navigation. The charted depth may be guaranteed without removing that material (FONTEIN et al., 2006). The layer in the harbour may be kept in its natural balance in situ, by using a new concept of dredging system. The question of whether the technique developed in a given harbour can be adapted for other harbours with different grain size distribution rises. In France, the River Seine carries an average suspended load of about $200 \mathrm{mg} / \mathrm{l}$ in the water column. During certain tidal phases (ebb tide) the concentration can reach up to $450 \mathrm{mg} / \mathrm{l}$. Because of the density difference this suspended material has the nature of quickly entering so-called calm zones as the entrance of Tancarville channel located on the Seine estuary. So, fluid mud remains there unaffected for a long time, start dewatering and interparticle bonds progressively reform leading to a steady rise in shear strength.

\section{Nautical depth concept}

Nautical depth concept is achieved when very soft mud is allowed within the nautical profile, provided safe shipping can be guaranteed. The definition of the nautical depth was made depending on only one parameter: the yield point. High concentrated flows formation is made of high concentrated suspensions of solid material together with a low density that have only a slight tendency to consolidate. The close spatial contact between the single particles is filled with microbial slime. Although the generated slime fills the gaps between the particles, it significantly reduces the internal friction and causes them to stay in suspension longer. The use of a unique relation of nautical bottom to a density level is a simplification of the problem, while the rheological properties, like shear strength and viscosity, are the direct parameters influencing navigational characteristics. However, in order to detect the elevation of the relevant bottom level, and to ensure the navigable conditions, knowledge on the in-situ mechanical properties of the sediment is required (BUCHANAN, 2005). The main parameter for navigational purposes is the initial resistance of the mud, when deformed. This is represented by the initial stiffness, the yield-strength. Due to the thixotropic time dependency the yield-stress is not uniquely related to the mud density.

\section{Rheological characteristics of sediment}

\subsection{Geotechnical parameters}

This study involves sediment collected in the entrance of the waterway of Tancarville (France) channel. The sediment was extracted at the sea bed surface using a grab and the pooled samples were homogenized and stored at a temperature close to $4^{\circ} \mathrm{C}$. This so-called calm zone is the largest retention zone for the suspended material, leading to intensive dredging. The quick consolidation of these materials makes dredging 
operations consistent. The physical parameters of dredged sediments have been studied experimentally in laboratory. Used material is mainly silt (87\%) with a low fraction of clay (3\%) and its grain size extends up to $500 \mu \mathrm{m}$. It is described as cohesive finegrained sediment with a high plasticity (index close to 43). The wet density is close to 1.37 and the organic matter content is about $11.5 \%$.

\subsection{Rheometer tests and analysis}

The sediment is defined as a fluid mud which is generally described as a cohesive finegrained sediment suspension with a concentration below that required for the formation of important soil structure (USAEWES, 1992). The amount of particles in the suspension influences the density and the mechanical (visco-elastic) properties and can best be described as pseudo-plastic or plastic liquids, being a liquid with a yield point. These suspensions exhibit both solid and liquid behaviour. When shear stress exceeds the yield stress the suspension will flow. The ability of the sediment particles to form bonds has an effect on its behaviour. This increase of yield-strength and viscosity with time is referred to as thixotropy (PHAM VAN BANG et al., 2007). In rheometric parallel plate test performed on the sediment, the sediment viscosity increases till a threshold value from which it falls down to zero value. This critical value of stress (yield strength) is associated with the beginning of sediment change behaviour, from visco-elastic material to solid suspension before fluidization. The tested suspensions exhibit both solid and liquid behaviour. For low shear stress there is no or limited flow, i.e. the viscosity is very high, and when shear stress exceeds the "yield stress" the suspension will flow and the viscosity is reduced to a lower level. From the laboratory tests it was observed that the remolded yield-strength and shear thinning increases with decreasing water content. This relation is assessed with parallel plate and cylindrical tests. As suggested for Emden port sediments (WURPTS \& TORN., 2005), the shear stress must be lower than 100 Pa for navigability concern. So, Tancarville sediment can be considered navigable when its density does not exceed $1.3 \mathrm{t} / \mathrm{m}^{3}$. These tests provide a first order approach of the in-situ rheological values. It does however not account for the time dependent thixotropic behaviour. Rheometer tests performed using rest duration of 20 hours indicate the increasing of maximum viscosity and shear thinning from $290 \mathrm{kPas}$ and $60 \mathrm{~Pa}$ to $440 \mathrm{kPas}$ and $110 \mathrm{~Pa}$, respectively. Figure 1 displays the results of variation of critical shear stress (value beyond which sediment behaves as a fluid) with solid concentration. The steep increase of the shear rate curves indicate which shear stress will destroy the internal structure of the moving sediment body, and when this occurs underwater, will enforce sediment resuspension. The speed of the flow can be calculated from the shear stress dependent viscosity and in combination with the yield point values and the limits of sediment particle cohesion, dredging techniques can be adjusted to different kinds of mud materials. Owing to this decrease of viscosity over time, less effort is needed for, e.g. pumping or traversing through the substance, than would be required. 
Côtes méditerranéennes menacées :

Risques et défis dans le contexte du changement climatique

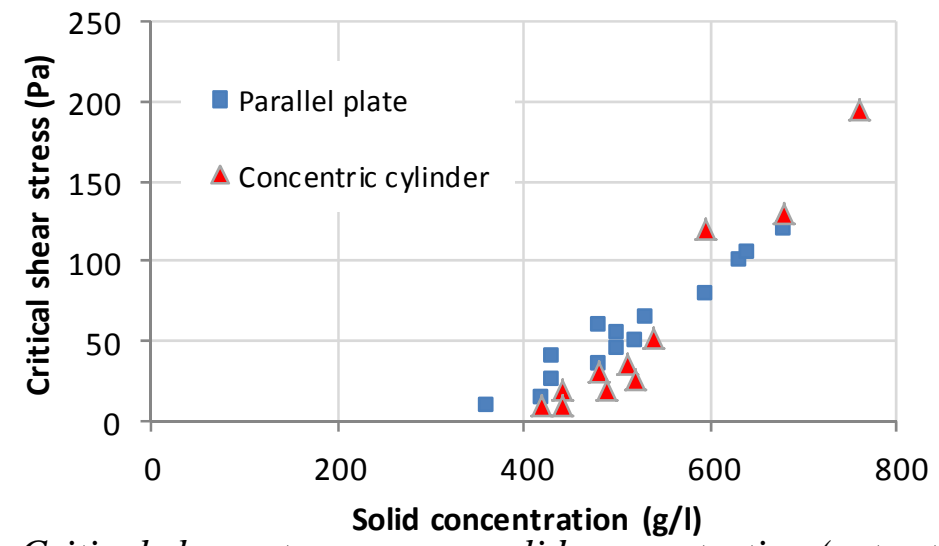

Figure 1. Critical shear stress versus solid concentration (rate strain controlled).

\section{Conclusions}

Rheometric tests performed in laboratory allowed to assess the suitability of remoulded sediments to reach low shear resistance without endangering the safe shipping by adequately assessing the rheological/mechanical characteristics. In addition reliable information about the "stiffness" of sediment layers would open up new strategies in maintenance dredging. The results show that the remolded yield-strength and shear thinning increase with decreasing water content. The computed viscosity curves (flow curves) are derived from each applied shear stress value versus each measured corresponding shear rate value. These curves show that this mud material will be able to flow when external shear stress exceeds about $30 \mathrm{~Pa}$ and this mud will lose its internal strength completely at shear stress values about $150 \mathrm{~Pa}$. The samples taken from the Tancarville waterway to check navigability have had densities of more than $1.4 \mathrm{t} / \mathrm{m}^{3}$. The dredging method which is applied must shows that the material can be navigable up to a yield point of $120 \mathrm{~Pa}$ if its density is lowered to less than $1.3 \mathrm{t} / \mathrm{m}^{3}$.

\section{References}

BUCHANAN L. (2005). Difficulties of surveying in fluid mud, the effect on bathymetry of suspended sediments in the water column. Hydro-International, Vol. 9, n ${ }^{\circ} 6$.

FONTEIN W., WERNER C., WAL J. (2006). Assessing nautical depth including direct viscosity measurements. Dredging and Sustainable Development CHIDA - 2nd International Dredging Congress May 17-18, 2006, Guangzhou, China.

PHAM VAN BANG D., OVARLEZ G., TOCQUER L. (2007). Effet de la densité et de la structuration sur les caractéristiques rhéologiques de la vase. La Houille Blanche n², pp 85-93. http://dx.doi.org/10.1051/hb:2007023

USAEWES -U.S. Army Engineer Waterways Experiment Station- (1992). The viscous Characteristics of channel-bottom muds. Dredging research technical notes, DRP-2-04. WURPTS R., TORN P. (2005). 15 Years' Experience with fluid mud: Definition of the nautical bottom with rheological parameters. Terra et Aqua, $n^{\circ}$ 99, pp 22-32. 